\title{
Consumo de nuevas sustancias psicoactivas: un reto para el sistema de monitoreo y atención en salud
}

\author{
Ricardo Sánchez-Huesca', Liliana Templos-Núñez' \\ 'Centros de Integración Juvenil, A.C.
}

Las nuevas sustancias psicoactivas (NSP) son sustancias de abuso en forma pura o preparada no incluidas en las Convenciones Internacionales que suponen una amenaza a la salud pública. Comprende sustancias utilizadas en medicina o veterinaria usadas como psicotrópicos. El Observatorio Europeo de las Drogas y las Toxicomanías (EMCDA, por sus siglas en inglés) menciona que 2014 y 2015 fueron los años en los cuales se detectaron más NSP y a partir del 2016 se estabilizaron. El Informe Mundial de Drogas de la Organización de las Naciones Unidas de 2019 indica que a diciembre de 2018 se habían identificado 892 nuevas sustancias psicoactivas en 124 países (UNODC, 2019).

Los principales grupos de NSP detectados son cannabinoides sintéticos, catinonas sintéticas, fenetilaminas, aminoindanos, triptaminas, piperazinas, ketamina y sustancias tipo feniciclidina, opioides y sustancias de origen vegetal. La mayoría son drogas sintéticas con efecto similar a las "tradicionales" como cannabis, cocaína, anfetamina, benzodiacepinas, heroína, LSD, éxtasis o metanfetamina.

Dentro de las NSP se encuentran también productos veterinarios, medicamentos de prescripción y las llamadas drogas inteligentes, como los potenciadores de las capacidades cognitivas, sexuales, del estado de ánimo y los suplementos para perder peso. La compleja composición química de algunas de esas y su frecuente combinación con otras sustancias "tradicionales" da como resultado efectos físicos y psicoactivos muy variados, en ocasiones impredecibles y potencialmente mortales.

Entre los factores asociados a la amplia diseminación de las NSP se encuentra su condición legal, bajo costo, distribución en redes sociales y tiendas naturistas, así como la baja percepción de riesgo en su consumo. La volatilidad en el mercado es otro de los factores que dificulta su regulación; en cuanto se detecta una sustancia, se introduce otra con efectos semejantes, cuyos precur- sores son legales. Existe evidencia de que la mayor producción de NSP ocurre en China e India, desde donde son transportadas a otros países. Con el fin de encubrir su verdadera naturaleza, en ocasiones se envasan y comercializan bajo etiquetas como "productos químicos de investigación" o como suplementos alimenticios, lo cual dificulta e impide su fiscalización y regulación. Las NPS son fabricadas y distribuidas sin ningún control de calidad, son probadas directamente en los consumidores (Guirguis, 2017) y las reacciones a las mismas determinan la permanencia o salida del mercado.

El mayor uso de NSP ocurre en grupos particulares y en contextos recreativos o encuentros sociales relacionados con un estilo de vida determinado, como es el caso de los psiconautas, quienes asisten a fiestas denominadas rave o festivales musicales. Son personas que desean explorar el efecto del consumo de ciertas sustancias sobre la mente y la percepción, por lo que constantemente están en la búsqueda de nuevos compuestos que les permitan alterar la conciencia y, por lo general, adquieren las NSP a través de entornos virtuales que no están regulados (EMCDA, 2015) y a través del darknet (red oscura). El darknet es un espacio en la red donde se realizan intercambios virtuales y mercancías y se preserva el anonimato de los usuarios. Es en estos ambientes donde se presenta el tráfico de NSP y la regulación de la compra-venta representa un desafío. Otro grupo de consumidores de NSP son los usuarios que las buscan con efectos similares a los de las drogas ilícitas para evitar las consecuencias e implicaciones legales, con el beneficio de un costo más bajo, disponibilidad y potencial de nuevas experiencias.

En la atención y reducción del daño por consumo de NSP es necesaria la puesta en marcha de diferentes acciones. La primera podría ser establecer una clasificación consensuada de estas sustancias; esta convención permitiría llevar a cabo estudios de corte epidemiológico para conocer la magnitud del mercado y

\footnotetext{
Autor de correspondencia:

Ricardo Sánchez Huesca

Director General Adjunto Normativo. Centros de Integración Juvenil, A.C.

Correo electrónico: dga.normativa@cij.gob.mx y sanchezhuesca_ricardo@hotmail.com

doi: 10.28931/riiad.2020.1.01
} 
del consumo y así poder regularlo y atender a sus usuarios. En segunda instancia, es importante capacitar a los profesionales de la salud con el fin de que conozcan las NSP, sus efectos y consecuencias, y para que sean capaces de reconocer su uso evitando su enmascaramiento con otras sustancias tradicionales. En algunos países europeos la identificación de los compuestos químicos a través de correo postal o de puestos itinerantes en fiestas y discotecas ha demostrado efectividad para informar al usuario sobre qué compuesto químico está consumiendo con el objetivo de que él mismo tome decisiones informadas con respecto a continuar o no su consumo. La tercera acción se centraría en el diseño de programas preventivos y de tratamiento específicos para las NSP. La evidencia sugiere que las acciones terapéuticas disponibles para las sustancias reguladas son la base para la atención de las NSP; queda aún por determinar qué acciones son particulares a éstas.

El tráfico y consumo de nuevas sustancias psicoactivas ha estado ya en el radar de los sistemas de salud internacionales desde hace algún tiempo; sin embargo, es necesario que cada país monitoree su uso e inicie su atención específica para evitar que se conviertan en un problema de salud pública.

\section{REFERENCIAS}

Guirguis, A. (2017). New psychoactive substances: a public health issue. International Journal of Pharmacy Practice, 25, 323-325. doi: 10.1111/ijpp.12313

European Monitoring Centre for Drugs and Drug Addiction. (2015). New Psychoactive Substances in Europe An Update From the EU Early Warning System. Luxembourg: Publications Office of the European Union.

Observatorio Europeo de las Drogas y las Toxicomanías (2019). Informe Europeo sobre Drogas Tendencias y novedades. Luxemburgo: Oficina de Publicaciones de la Unión Europea.

United Nations Office on Drugs and Crime. (2019). World Drug Report 2018. Vienna: United Nations Publications. 